\title{
RELAÇÕES ENTRE ESFERAS GOVERNAMENTAIS NA EDUCAÇÃO E PDE: O QUE MUDA?
}

\author{
SILKE WEBER \\ Programa de Pós-Graduação em Sociologia da Universidade Federal de Pernambuco \\ silke@elogica.com.br
}

RESUMO

O texto focaliza a proposta de relacionamento entre as três esferas de poder - União, estados e municípios - no provimento da qualidade da educação básica, que consta do Plano de Desenvolvimento da Educação, lançado pelo Ministério da Educação em 2007. Entre as esferas governamentais, ao longo das últimas décadas, são assinalados alguns avanços e desdobramentos nas relações, que devem culminar na construção do Sistema Nacional de Educação. Destaque é dado a alguns dos desafios decorrentes do compartilhamento da União nos acertos locais de elevação dos padrões de qualidade, sendo anotadas possíveis formas de regulação que a eles serão associadas. A definição de parâmetros para institucionalizar, em todo o país, o regime de colaboração e controle social da educação, é percebida como passível de transformar a educação escolar em eixo central de um projeto de Nação.

EDUCAÇÃO BÁSICA - QUALIDADE DE ENSINO - POLITICAS EDUCACIONAIS - SISTEMA NACIONAL DE EDUCAÇÃO

\section{ABSTRACT}

RELATIONSAMONG GOVERNMENTAL SPHERES ONEDUCATION DEVELOPMENTPLAN: WHAT CHANGES? This paper focuses on the relationship between the three spheres of power - Union, State and County/Municipalities - proposed in 2007 by the Ministry of Education in its Education Development Plan. The aim of this plan is to improve the quality of basic school education. We start by listing some advance and developments in the relationship maintained among the various governmental spheres that have taken place in the last decades. These should lead to the construction of the National System of Education. Emphasis is given to some challenges generated by the Union's participation in local agreements in order to increase quality's standards, indicating, also, possible ways of regulating such agreements. The definition of parameters for institutionalizing the regime of collaboration and social control of education on a national level is perceived as bound to transform basic school education into the main axis of a project of Nation.

BASIC EDUCATION - TEACHING QUALITY - EDUCATIONAL POLICIES - NATIONAL SYSTEM OF EDUCATION

Versão modificada de texto originalmente apresentado no Seminário Itinerante: o PDE em Debate nas Universidades Públicas Paulistas, em outubro de 2007. 
A edição recente do Plano de Desenvolvimento da Educação - PDE pelo Ministério de Educação trouxe, mais uma vez, a questão da educação formal para a ordem do dia. Desta feita, entretanto, a visibilidade dada à questão educacional é estabelecida em um marco que associa, de modo explícito, a relação entre educação escolar e projeto de sociedade, tendo como referência principal a síntese do debate em favor da democracia operada pela Constituição Federal de 1988. Assim, o Plano de Desenvolvimento da Educação reconhece a educação escolar como um direito social básico a ser assegurado pelo Estado, e privilegia a visão de formação humana como aspecto indispensável para concretizar a presença ativa do cidadão no mundo, fundamentada também na organização do pensamento e no desenvolvimento da reflexão crítica.

Pressupondo existir uma relação dinâmica entre processo de socialização e processo de individuação, o PDE concebe a educação formal como um caminho que articula e enlaça momentos e etapas do desenvolvimento pessoal e individual com a edificação de uma sociedade livre, justa e solidária, na perspectiva de simultaneamente promover a construção da autonomia individual e das instituições. Nesse sentido, o Plano se insurge contra a visão fragmentada que tem historicamente presidido a política educacional e propõe uma nova abordagem, baseada na concepção sistêmica de educação escolar.

Sob tal abordagem, as questões de atendimento, acompanhamento, avaliação e controle social articulam-se organicamente e é em torno delas e em razão delas que se mobilizam os diversos atores sociais e agentes governamentais concernidos, que devem pactuar responsabilidades entre si, estabelecer metas, controlar a execução do que tiver sido definido como encargo de cada um, realizar os necessários ajustes. Em suma, o PDE propõe a formulação de uma política de Estado com sustentação na sociedade e na esfera pública, independente do grupo no poder, de forma que atores sociais e poder público se coordenem para assegurar a educação como direito humano inalienável.

Sem entrar no mérito de tal concepção, vale destacar alguns aspectos porque neles está embutido o compromisso com a efetivação social do acesso ao conhecimento e aos significados construídos pela humanidade, ao longo de sua história, e o estímulo ao estabelecimento de relações entre esses conhecimentos e significados com aqueles presentes na vida cotidiana pessoal, cultural e de trabalho. Entre eles ganha relevo o fato de os sucessivos patamares de complexidade, que são atingidos nesse processo de re-significação, promove- 
rem, nas gerações escolares, definições ou reafirmações de sua presença no mundo, impondo a busca de novos padrões de qualidade da ação educativa sistemática.

A materialização de tais padrões, produto de processo multifacetado, requer, simultaneamente, condições escolares adequadas para as diferentes fases do desenvolvimento humano e para os níveis e modalidades de ensino e de formação, de profissionalização do docente (condições de trabalho e remuneração compatíveis com a relevância social de sua tarefa), condições de gestão democrática da escola e da política educacional, bem como avaliação periódica do processo pedagógico e participação da comunidade. Requer ainda a articulação entre esferas governamentais constituindo, certamente, caminho promissor para promover políticas educacionais de corte nacional que, pela convergência de propósitos, venham concretizar a qualidade da educação formal nos diferentes níveis e modalidades, como um direito social básico.

Antes, porém, de discutir sentidos e ações propostos no PDE, vale fazer a esse respeito uma rápida incursão na história do relacionamento entre esferas governamentais, para localizar avanços e recuos e poder fundamentar críticas e reflexões sobre a política educacional proposta no Plano.

\section{RELAÇÃO ENTRE ESFERAS GOVERNAMENTAIS: TÔNICA CONSTANTE DAS POLÍTICAS EDUCACIONAIS NO BRASIL}

A idéia de descentralização na área da educação, conforme Cury (1997), relaciona-se com o debate sobre direitos sociais e com a luta democrática, cujos marcos podem ser identificados nos anos 1940, no contexto da oposição ao Estado Novo e no âmbito da luta em prol da democracia contra o arbítrio representado pelo regime militar do período 1964-1986, quando a proposta de descentralização efetivamente se impôs, particularmente após a promulgação da Constituição Federal de 1988.

Nessa discussão, permeada pela perspectiva política de manutenção do poder, tal como ocorreu durante os governos militares, ou pelos anseios da democratização da gestão pública, ganhou relevo a municipalização dos anos iniciais da educação escolar obrigatória. A questão tem sido aprofundada no debate sobre a legislação relativa à educação que se seguiu à Constituição Federal de 1988, e recebeu formulação específica na Emenda Constitucional n. I 4, de 
setembro de 1996, e na criação do Fundo de Manutenção e Desenvolvimento do Ensino Fundamental e de Valorização do Magistério - Fundef - em dezembro desse mesmo ano. Na Constituição, ficou consagrada a municipalização do ensino fundamental, visão que se consolidaria na Emenda Constitucional n. I4. Dividindo tarefas, responsabilidades e recursos, a mesma Constituição atribuiu à União a responsabilidade em relação ao ensino superior e às escolas técnicas federais, além da função supletiva e distributiva junto a estados e municípios; aos estados, além do ensino fundamental, confirmou a atribuição da responsabilidade de manutenção do ensino médio. Tais dispositivos têm sido analisados por estudiosos, nos últimos anos, como aspectos impulsionadores de competição entre os entes federativos, em detrimento do suposto regime de colaboração, igualmente definido pela Constituição como principal característica do regime federativo brasileiro.

Com efeito, a Constituição Federal, no artigo 21 I, dispôs que as esferas de governo se organizariam em regime de colaboração, referendando a estrutura federativa fundada na cooperação, embora não tenha delimitado claramente as respectivas responsabilidades, o que é realizado, oito anos após, pela Lei de Diretrizes e Bases da Educação Nacional - LDB -, que estabelece as incumbências das três esferas governamentais no provimento da educação formal.

Estudo recente de Castro e Duarte apresentado na Reunião Anual da Anped, em 2007, indica que não somente a colaboração entre estados e municípios aprofundou a segmentação de políticas e acentuou as diferenças locais, como também restringiu o foco das políticas educacionais nos últimos dez anos ao ensino fundamental como questão afeta aos municípios, esfera para a qual recursos financeiros foram estendidos, enquanto o ensino de nível médio e o de nível superior tiveram perdas financeiras importantes, em razão de a União ter deixado de executar a sua ação supletiva e redistributiva.

Pode-se afirmar que a reconfiguração do federalismo brasileiro em relação à educação foi a tônica dada à política educacional por intermédio de um conjunto legislativo orgânico: a Constituição de 1988, a Emenda n. 14, a Lei do Fundef, a LDB e o Plano Nacional de Educação - PNE. Tais mecanismos, ao promoverem um reordenamento político e institucional em favor da municipalização do ensino fundamental, ensejaram também, conforme antecipou Barretto (1990, 1992, 1995), a queda de qualidade do ensino e o desmantela- 
mento dos serviços públicos educacionais. Certamente há também avaliações positivas desse processo, a exemplo da opinião de Martins (2003), que vê na municipalização do ensino fundamental a possibilidade de desenvolvimento de experiências alternativas, delimitadas territorialmente e beneficiadas pela proximidade do poder. Outras interpretações têm identificado, na municipalização, avanços na participação social no campo da educação em nível local.

Fica evidente assim quão difícil tem sido, do ponto de vista da implantação de políticas educacionais, a efetivação do que fora proposto por Oliveira, em 1991 - a articulação das redes públicas "a partir de políticas pactuadas entre as diversas esferas jurídico-administrativas, nas quais fossem explicitadas as respectivas responsabilidades, com garantia, entretanto, da unidade do processo pedagógico". Tal proposta, que se aproxima daquela formulada por Barretto quando alertava para a necessidade de que essa divisão de competências fosse feita em proveito de um melhor atendimento ao conjunto da população, indicava que a articulação daquelas esferas públicas deveria torná-las "menos concorrentes" e "mais colaboradoras" e "interdependentes", sugerindo a criação de redes públicas associadas a amplos processos de negociação. Esta era, aliás, uma das preocupações dos estudos do início dos anos 1990, que somente consideravam ser possível o fortalecimento do sistema federativo "quando as diversas esferas governamentais apresentassem alto grau de integração, solidariedade, identidade de propósitos quanto às necessidades educacionais". Este poderia ser considerado um dos pontos de partida do PDE que, apresentandose como uma política nacional de educação, proporia o redimensionamento das ações entre os entes federados.

\section{DESAFIOS SUSCITADOS PELO PDE}

Entretanto, o PDE parece não ter se inspirado em experiências de gestão educacional pregressas, tais como a descentralização negociada, a articulação, colaboração, parceria, integração, co-responsabilidade coordenada, descentralização coordenada, gestão compartilhada (fórmula adotada em Pernambuco), até porque a forma de implementação do Fundef as tirou de pauta. Tais propostas vivenciadas por vários estados foram arroladas, entre outros, por Oliveira (|99|), para registrar projetos convergentes em seu conteúdo e com preocupação ou não de contar com a participação da sociedade civil organi- 
zada a fim de salvaguardar a unidade da educação escolar. O PDE, entretanto, parece deslocar esse foco para acentuar a necessidade de superar a ação segmentada, justificativa a que recorre com vistas a estabelecer as bases para uma nova política nacional de educação básica, fundada no respeito à autonomia das esferas estaduais e municipais, tendo como elo políticas acordadas "entre esferas públicas entre si, e entre estas e a sociedade civil organizada", mediante a sua inscrição em alguns dos 40 programas arrolados no Plano para estimular a "qualificação do processo de ensino e aprendizagem".

Assim, diferentemente do que aqui se denominam experiências pregressas, cujas políticas de articulação local eram consubstanciadas em planos estaduais e municipais de educação e no PNE - instrumentos que formalizavam e explicitavam tanto o conteúdo das políticas, como as formas de sua operacionalização, as fontes e o volume de recursos, e eventualmente funcionavam como canais para o acompanhamento sistemático dos planos estabelecidos -, o PDE propõe a criação do Sistema Nacional de Educação. Visa, deste modo, institucionalizar de forma unificada "a garantia do direito à educação" e proporcionar as condições para a definição de políticas educacionais "que promovam a inclusão social de forma articulada entre os sistemas de ensino".

Materializar a cooperação entre esferas governamentais e movimentos sociais em novas bases constitui certamente o principal desafio do PDE. Importa resumir, portanto, a proposta, para em seguida tentar abordar a pergunta que motivou esta análise: o Plano propõe novas formas de regulação?

Em primeiro lugar, vale destacar como aspecto positivo que os parâmetros para a construção de um Sistema Nacional de Educação que promova, de forma articulada, em todo o país, o regime de colaboração e o controle social da educação, deverão decorrer de amplo debate nacional que culminará na Conferência Nacional de Educação Básica. Como segundo aspecto positivo, cabe anotar a perspectiva republicana que norteia a proposta e que pressupõe a construção da unidade do sistema educacional "como sistema nacional", "salvaguardando multiplicidade e evitando uniformidade, mas enfrentando a desigualdade de oportunidades educacionais" "e considerando as necessidades de desenvolvimento econômico e social".

Ao reconhecer as conexões intrínsecas entre os diferentes tipos e modalidades de ensino e de formação, o PDE pretende potencializar políticas educacionais que se reforcem reciprocamente num mesmo "território". Consi- 
derando o compartilhamento de competências políticas, técnicas e financeiras, propõe também intervenções consentâneas, ou seja, acordadas, para assegurar a autonomia respectiva de cada uma das esferas de poder presentes no "território", concebido como lócus em que se dá o enlaçamento da educação com o desenvolvimento econômico e social.

Espera-se que esta intervenção consentânea, a se orientar certamente por regras explícitas e transparentes, passíveis de acompanhamento público e controle social, produza efeitos positivos à semelhança daqueles anotados na execução de políticas educacionais pactuadas entre estados e municípios, ao longo das décadas de 1980 e de 1990. O novo na proposta do PDE é o compartilhamento da União não somente nos acertos locais, mas no exercício de sua atribuição constitucional de coordenar e incentivar a definição e execução de políticas educacionais, e de desenvolver ação supletiva e distributiva na consecução da elevação dos padrões de qualidade no ensino oferecido no âmbito da educação básica. Essas tarefas seriam subsidiadas pela alocação de maior proporção do Produto Interno Bruto - PIB - para a educação escolar, a ser repassada automaticamente ou sob condições às escolas e redes educacionais, acréscimos a serem assegurados por intermédio do Fundo de Desenvolvimento da Educação Bássica - Fundeb.

Outro aspecto positivo é que a proposta de avaliação da educação básica passa a estabelecer conexões entre avaliação, financiamento e gestão, reportando-se à responsabilização com desdobramentos possíveis de mobilização social. A avaliação também contempla o desempenho do aluno e das unidades escolares, verificando se o conjunto dos elementos que compõem a escola e as atividades escolares está estruturado para a oferta de educação de qualidade.

Ora, conforme já assinalado, a construção da qualidade constitui processo multifacetado que requer, simultaneamente, condições escolares adequadas para o desenvolvimento das atividades pedagógicas; profissionalização docente consubstanciada, pelo menos, em jornada de trabalho que permita envolvimento com a tarefa educativa, no incentivo à formação continuada e à atualização constante, no intercâmbio entre pares, na disposição de material didático-pedagógico e na remuneração compatível com a relevância social do trabalho docente; gestão democrática da escola vivenciada em conselhos, colegiados, articulação com a comunidade e com entidades da sociedade civil em 
torno do projeto pedagógico; avaliação periódica dos resultados dos processos pedagógicos, técnicos e administrativos, presença ativa da comunidade escolar. A leitura de tais indicadores poderia sugerir novos elementos para a avaliação (e talvez para a regulação) da educação básica, uma vez que, até o presente, a avaliação pública tem consistido em diagnóstico ou descrição da situação escolar, com tendência a se fixar nos aspectos sinalizadores de baixa qualidade do ensino ministrado nas escolas de determinadas localidades ou regiões.

\section{NOVAS FORMAS DE REGULAÇÃO?}

A concepção de qualidade como processo multifacetado que envolve escola, professor, alunos, comunidade, políticas de ensino e políticas educacionais locais e nacionais necessariamente conduzirá ao estabelecimento de novos padrões de referência de qualidade aferidos por instrumentos que tenham a escola e a sua dinâmica como focos principais de análise. Trata-se, portanto, de induzir uma concepção de sistema educacional como estrutura voltada para assegurar a escola de qualidade. Ou seja, escola como lugar de ensino e de aprendizagem e de enriquecimento cultural, coordenado e dinamizado por professores e por aqueles que dão suporte a atividades pedagógicas, com vivência de padrões de gestão e administração específicos, voltados para articular o trabalho coletivo da comunidade escolar e daquela que a circunda, em direção ao desenvolvimento de propostas pedagógicas consistentes com a busca contínua de qualidade. Aspectos escolares e extra-escolares, portanto, são considerados em suas relações recíprocas, sendo as diretrizes de uma política educacional de Estado os principais elementos organizadores da escola, do trabalho docente, do atendimento ao aluno. Aliás, o próprio documento do PDE prevê a avaliação externa de estabelecimentos de ensino por meio de uma amostra representativa, certamente com o fito de neles intervir quando se mostrar necessário.

Além disso, a fixação de metas em relação ao Índice de Desenvolvimento da Educação Básica - Ideb -, mediante consulta a banco de dados e visitas de inspeção, conduzirá evidentemente ao acompanhamento contínuo do processo escolar, não sendo possível antever em detalhes o seu formato, embora fique patente a importância atribuída às condições escolares, tanto materiais como pedagógicas. Ora, condições materiais dependem, certamente, das condições 
socioeconômicas de onde estão localizadas as unidades escolares, ou seja, primordialmente elas dependem de fatores extra-escolares. As condições pedagógicas, se bem também se relacionem com o contexto social, remetem, por sua vez, a complexo aparato de formação docente - inicial e continuada -, acompanhamento e crítica da prática pedagógica, mas, sobretudo, à valorização da atividade docente consubstanciada em remuneração condizente e condições de trabalho adequadas - número de alunos por turma, jornada de trabalho, material didático disponível, incentivo ao intercâmbio, entre outros aspectos.

De todo modo, no PDE é anunciada uma Avaliação de Campo, instrumento voltado para a análise do sistema educacional, a ser realizada de forma compartilhada pelos entes federados e que abordará quatro dimensões: gestão educacional, formação de professores e dos profissionais de apoio escolar, infraestrutura, e cuja expectativa é aprofundar o relacionamento entre as esferas governamentais na efetivação de novos patamares de qualidade na educação. Tal proposta sugere a formulação de mecanismos de intervenção como, por exemplo, o processo de "acreditação" de unidades escolares, de professores e gestores e o subseqüente processo de intervenção em escolas que não estejam conseguindo realizar a sua tarefa específica.

Vale refletir sobre a dinâmica social que tal processo engendrará do ponto de vista político, financeiro e de gestão. No que concerne ao professorado, as universidades públicas, à semelhança de alguns países, certamente terão acrescidas às suas tarefas de formação inicial as de formação continuada, assim também como novos temas e problemas de pesquisas relacionados ao ensino e à educação.

É bem verdade que a avaliação necessariamente não subsidia ou conduz à regulação, embora forneça elementos importantes que possam justificar algum tipo de intervenção regulatória. O desenho inicial do PDE, entretanto, parece configurar uma urgência para acelerar mudanças concretas na forma pela qual hoje são ofertados tipos e modalidades de educação básica em várias regiões e localidades do país.

Importa anotar que a abertura de escolas é normalizada em cada sistema de ensino específico, segundo parâmetros e exigências estabelecidas pelos conselhos estaduais de educação e, mais recentemente, pelos conselhos municipais de educação. Isso, entretanto, não tem evitado que em nível estadual ou municipal persista a utilização de prédios inteiramente inadequados às tarefas 
educativas, nem o recrutamento de professores sem a formação requerida e submetidos a condições de trabalho que somente desvalorizam a tarefa educativa, entre outros aspectos.

A intervenção sugerida, portanto, adviria dos próprios avanços no conhecimento dos problemas educacionais e na sua localização, constituindo a Prova Brasil um exemplo disso, inclusive por fornecer elementos para articular desempenho do aluno e rendimento escolar (fluxo), permitindo a criação do Ideb. As mudanças no Censo Escolar, que passou a ser feito por aluno e não mais por escola, propiciam também informações para intervenções sempre que detectados problemas educativos em espaços geográficos determinados (territórios). O Ideb, ao permitir a identificação de redes e escolas públicas frágeis, obrigaria "a União a acionar a sua ação supletiva e assim intervir em favor do direito de aprender do aluno". Vale anotar o recurso ao conceito de "território" como estratégia de política educacional e à idéia de "arranjo educativo", este último conceito tomado certamente por analogia a arranjo produtivo, empregado no planejamento econômico atual. Não parecendo possível aproximar lógicas e dinâmicas tão diferentes, importa aprofundar este debate.

Assim, além de instrumentos que subsidiem a regulação, ou seja, a intervenção imediata capaz de assegurar à escola condições objetivas, proporcionar efetivamente a aprendizagem do aluno, é prevista a formulação de instrumentos jurídicos que permitam apoiar o compromisso de execução das metas estabelecido para o Ideb, o que pode ser entendido como mais uma sinalização da necessidade de regulação específica.

Por sua vez, é possível pensar que a implementação das diretrizes de Estado para a educação básica vai requerer, mais do que regulação, acompanhamento, pois é hoje consenso ser tarefa inerente dos entes públicos proporcionar educação de qualidade à população. É bem verdade que há divergências importantes quanto à interdependência de fatores relacionados, reivindicando-se para o docente lugar de destaque dessa tarefa, embora não como o único responsável pela superação dos problemas hoje apontados. Nesse sentido, a construção de novos patamares de qualidade dependeria, em grande parte, de sua valorização, a ser consubstanciada principalmente na concentração de sua jornada de trabalho em uma só escola e no recebimento de remuneração condizente, sendo a fixação do piso salarial nacional a sua pedra de toque. 
Três focos, conforme já assinalado, serão certamente objeto de cuidado especial: as instalações físicas das escolas - incluindo biblioteca e laboratórios; o desempenho pedagógico do professor e da gestão escolar; e o relacionamento com a comunidade, confirmando que o fazer escolar não se restringe aos seus muros, quando a escola os tem, mas constitui foco de preocupação nacional, e o seu enfrentamento exige interlocução e intervenção dos entes federativos, em regime de colaboração.

É nesse sentido que parece ser esperada a sustentabilidade das ações que congregam as esferas governamentais locais e estaduais. $\bigcirc$ que é proposto pelo PDE é um modelo de articulação entre os entes federados no sentido de fazer valer a vontade política de promover efetivamente a oferta de educação básica de qualidade como direito social básico. Diagnóstico, plano de ações articuladas em relação a metas estabelecidas em sintonia com o debate nacional e internacional, instrumentos de avaliação de campo, são caminhos que certamente alçarão a política educacional ao campo da racionalidade, do qual não estão excluídos instrumentos de controle e de intervenção. $\bigcirc$ que cabe perguntar é se tais instrumentos irão subsidiar (ou não) a regulação, atividade de Estado que visa ao ordenamento e desenvolvimento do conjunto das unidades escolares da educação básica, com o fito de oferecer os seus diversos tipos e modalidades de ensino em padrões de qualidade que se coadunem com as exigências inerentes à formação e ao exercício da cidadania requeridas pela sociedade brasileira atual.

\section{ALGUMAS CONSIDERAÇÕES A MAIS}

Dado que é obrigação do Estado ofertar educação básica, cabe à União, como uma das esferas do poder público, mediante o recurso a mecanismos que the são próprios, prestar assistência técnica e financeira necessária, conforme disposto na Constituição Federal, para estimular o aprimoramento e o redirecionamento de objetivos da escola e a sua focalização como instância socializadora do saber, do conhecimento, da cultura, da arte e da tecnologia produzidos pela humanidade, ao longo de sua história. Regras, portanto, precisam ser estabelecidas e observadas, de modo a se tornarem referência para uma escola de qualidade, de tempo integral, dotada de professores com a formação requerida e com material didático-pedagógico adequado, com 
atuação em condições compatíveis com o processo de ensino e aprendizagem e com a sua presença social. Educação e escola, portanto, não mais concebidos ou praticados como instrumento de conservação do poder local, canal de ascensão social, condição para o desenvolvimento econômico e social, meio de organização político-partidária, mas como elemento fundamental da construção de um país democrático.

Parece claro que o PDE, na sua conformação de longo prazo, e de adesão a compromissos com metas estabelecidas, ao ter a sua execução monitorada social e institucionalmente, impulsionará a constituição do Sistema Nacional de Educação "como elemento unificador da ação do conjunto dos entes federados e da participação ativa da sociedade na garantia do direito à educação", tal como formulado no Documento referência, da Conferência Nacional de Educação, prevista para abril de 2008.

É esperado que a definição de parâmetros para institucionalizar, em todo o país, o regime de colaboração e controle social da educação promova a educação escolar como eixo central de um projeto de Nação. Os temas que the concernem e que se voltam para a gestão e o financiamento de políticas educacionais em regime de colaboração - Fundeb e o desenvolvimento dos sistemas de ensino, transferência de recursos e compromisso assumido, vinculação de recursos financeiros e manutenção e desenvolvimento do ensino - são aqueles que vêm perpassando o debate nacional e a formulação de políticas educacionais nas três últimas décadas. Nessa perspectiva é possível afirmar que o PDE:

- Sistematiza e aprofunda debate e prática histórica de estados e municípios.

- Sinaliza a educação básica como política de Estado.

- Enfatiza a articulação e os acordos em detrimento de modelo único associado a punições e classificações.

- Reconhece parceiros na implementação das políticas de Estado e apresenta a União como solidária na efetivação de intervenções educacionais locais.

- Amplia o sentido de regime de colaboração pelo estabelecimento de metas pactuadas fundadas em diagnóstico.

- Aposta em mecanismos de acompanhamento e de controle como forma de realizar ajustes e intervenções preventivas. 
- Suscita o apoio da instância produtora de conhecimentos, a universidade, na formação docente e na fundamentação, execução, monitoramento e avaliação de políticas educacionais.

- Terá repercussão positiva sobre a dinâmica do trabalho escolar e reconhece o professorado como profissional, com direito à remuneração condigna e condições de trabalho compatíveis.

- Devolve à sociedade a sistematização de demandas históricas, a reconhece como parceira indispensável e a convoca a monitorar a materialização da qualidade da educação como projeto nacional.

\section{REFERÊNCIAS BIBLIOGRÁFICAS}

BARRETTO, E. S. S. Descentralizar e redistribuir nos sistemas de ensino. Cadernos de Pesquisa, São Paulo, n.95, p.73-78, nov. 1995.

O Ensino básico no Brasil visto do ângulo das políticas públicas. In: FRANCO, M. L. B.; ZIBAS, D. (orgs.) Desafios da educação na América Latina. São Paulo: Cortez, 1990. p.30I-324.

Onde se quer chegar com a municipalização do ensino fundamental? Cadernos de Pesquisa, São Paulo, n.80, p.5I-55, fev. 1992.

BRASIL. Congresso Nacional. Constituição Federal. Brasília. 1988.

Emenda Constitucional n. 14, de 13.9.1996. Brasília, 1996.

BRASIL. Leis e decretos. Lei n. 9.324, de 23. 12 . 1996: Diretrizes e Bases da Educação Nacional. Brasília, 1996.

Lei n.9.424, de 24.12.1996: Fundo de Manutenção e Desenvolvimento do Ensino Fundamental e de Valorização do Magistério. Brasília, 1996.

Lei n. 10.712, de 9.1.2001: Plano Nacional de Educação. Brasília, 2001.

Lei n. 11 .494, de 20.6.2007: Fundo de Manutenção e Desenvolvimento da Educação Básica e de Valorização dos Profissionais da Educação Básica. Brasília, 2007.

BRASIL. Ministério da Educação. Plano de Desenvolvimento da Educação: razões, princípios e programas. Brasília, 2007.

Plano de desenvolvimento da educação: programas. Brasília, 2007. Disponível em: www.mec.gov.br. Acesso em: 5 out.2007. 
BRASIL. Ministério da Educação. Documento de referência da Conferência Nacional da Educação Básica. Brasília, 2007. Disponível em: www.mec.gov.br. Acesso em: 5 out.2007.

CASTRO, J. A.; DUARTE, B. de C. Descentralização da educação pública no Brasil: evolução dos gastos e matrículas. [Trabalho apresentado na 30ª Reunião Anual da ANPEd, out. 2007] Disponível em: www.anped.org.br. Acesso em: 28. out.2007.

CURY, C. R. J. Leis nacionais da educação: uma conversa antiga. In: CURY, C. R. J.; BAHIA HORTA, J. S.; BRITO, V. L. A. de (orgs.) Medo à liberdade e compromisso democrático: LDB e Plano Nacional da Educação. São Paulo: Editora do Brasil, 1997. p.7-28.

MARTINS, A. M. Uma análise da municipalização do ensino em São Paulo. Cadernos de Pesquisa, São Paulo, n. I20, p.221-238, nov. 2003.

OLIVEIRA, M. das G. C. Continuidades e descontinuidades das políticas de educação básica: o caso de Pernambuco. Recife: Editora Universitária da UFPE, 2006.

Novas relações estado/municípios no campo da educação. In: WEBER, S. (org.) Democratização, educação e cidadania: caminho do Governo Arraes ( 1987 - 1990). São Paulo: Cortez, 1991. p.49-76.

Universalização do ensino básico com qualidade: um direito social. Em Aberto, Brasília, v.7, n.39, p. 15-21, 1988.

PERNAMBUCO. Secretaria de Educação e Esportes. Plano estadual de educação: 19881991. Recife: Inojosa, 1988. Plano estadual de educação: 1996-1999. Recife, 1996. Política educacional de Pernambuco: 1995-1998. Recife, 1998.

Recebido em: dezembro 2007

Aprovado para publicação em: dezembro 2007 